\title{
The Age of Transition
}

\author{
Giovanni A. Fava \\ Department of Psychiatry, University at Buffalo, State University of New York, Buffalo, NY, USA
}

While a fourth-year resident in psychiatry in Italy, I was confronted with the challenges of running an inpatient psychiatric unit as an attending physician in the United States. I obviously felt overwhelmed by that task, which largely exceeded my clinical experience and knowledge. I had a supervisor and mentor who could come once per week to the ward for $1 \mathrm{~h}$. I soon realized that $1 \mathrm{~h}$ was totally insufficient and pleaded for time. My supervisor, an outstanding clinician and scientist, replied that, unfortunately, a longer time was not possible, but he could take me to a place where I could get important help. I was very curious about the statement; we left the ward and I followed him. He took me to the medical library, in those days full of printed journals and books. He said: "You can find all replies to your questions here. The only thing is that it may not be easy to discern what is helpful and what is not. But you will learn it soon.” Every day, when I finished my clinical duties, I went to the library and left only when hunger became unmanageable and I had to go to dinner. Indeed, I soon realized that articles on a specific topic might be very different, not only in the conclusions, but also in their clinical implications. There were articles (whether experimental studies or reviews) that reflected the clinical insights of the authors and the data supporting those insights. There were articles that seemed to be meaningless to me (so what?). I learnt to recognize certain authors and, by doing this, the range of my consultants increased. While reading and consulting articles and books, I always had the feeling that improvement in my performance was a function of upgrading my clinical judgment, by trying to capture how senior colleagues and nurses came to certain conclusions, and of incorporating knowledge that could help me dealing with complex and difficult clinical challenges.

Not surprisingly, many years later, as an editor, I was always looking for papers that were characterized by the "clinical factor": the degree and extent to which a journal article provides information to the clinician that may improve his/her practice [1]. For many years, in this journal Richard Balon has been trying to extract, from the immense psychiatric literature, the articles that had a "clinical factor" [2], with increasing difficulties, to the point that a couple of years ago we decided to stop. The young psychiatrist pictured at the beginning would have trouble finding papers that could answer questions and provide new insights. What would he/she look at? The Cochrane reviews? The systematic reviews and meta-analyses of prodigal experts who have no familiarity with the clinical process, and, often, not even with the struggles of performing original investigations? Influential randomized trials are generally done by and for the benefits of the industry; guidelines serve vested interests; national and federal research funds are directed almost exclusively at research with little relevance to health outcomes [3].

This journal takes its unique characterization from the strong clinical focus and the emphasis on innovations at the interface of behavioral and medical sciences [4]. Not surprisingly, many positions and papers were ahead of their times and preceded a more general awareness of the problem. At times, it was just a matter of a few years. Examples in the nineties were the recognition of the problem of financial conflicts of interest [5] before the scan- karger@karger.com

(c) 2020 S. Karger AG, Basel

www.karger.com/pps

Karger!
Giovanni A. Fava

Department of Psychology, University of Bologna Viale Berti Pichat 5

IT-40127 Bologna (Italy)

giovanniandrea.fava@unibo.it 
dals of the following decades; the discovery of the clinical value of psychological well-being [6], prior to the advent of positive psychology; and the importance of subclinical symptoms in mood and anxiety disorders, leading to a redefinition of the concept of recovery [7]. In other instances, recognition took much longer, as in the case of iatrogenic effects of antidepressant drugs [8], but, at last, it had to be acknowledged (e.g., "withdrawal" and not "discontinuation" syndromes) [9].

A few years ago, we challenged the conceptual framework of evidence-based medicine (EBM) [10], something that Feinstein and Horwitz [11] had done 2 decades earlier. EBM certainly made an important contribution to questioning unsubstantiated therapeutic claims. The time had come, however, to become more aware of its considerable limitations, including overall reductionism and insufficient consideration of problems related to financial conflicts of interest [10].

The clinical inadequacy of EBM extends over different areas. One is concerned with the appraisal of the effects of therapy. Treatment outcome is the cumulative result of the interaction of several classes of variables with a selected treatment: living conditions (housing, nutrition, work environment, social support), patient characteristics (age, sex, genetics, general health conditions, personality, well-being), illness features and previous therapeutic experience, self-management, and treatment setting (physician's attitude and attention, illness behavior) [12]. Such variables may be therapeutic or counter-therapeutic. In certain patients, their interactive combination may lead to clinical improvement, whereas in other cases it may produce no effect and, in a third group, it may lead to worsening of the condition [13]. The changed spectrum of medical disorders (shifted toward aging, chronicity, and comorbidity) and the inter-individual differences in health priorities make the focus on single diseases, as EBM does, potentially misleading. Indeed, there is growing awareness that the aim of treatment should refer to personal goals (from attainment of cure to prevention of recurrence, from removal of functional impairment to alleviation of symptoms) [14]. Further, EBM is geared to highlight benefits much more than harms, and commercial interests may drive this tendency [15]. The net result is the production of authoritarian guidelines, with the suppression of pluralism. In such guidelines, endorsed by scientific societies liable to conflicts of interest, the prescribing clinician is driven by an overestimated consideration of potential benefits, paying little attention to the likelihood of responsiveness and to potential vulnerabilities in relation to the adverse effects of treatment [15]. Finally, a major omission at a time of medication overload [16] is the lack of consideration of the role of iatrogenic components [17]. It has been argued, for instance, that current diagnostic methods in psychiatry refer to patients who are drug free, and they do not take the issue of iatrogenic comorbidity into consideration. They are suited for a patient who no longer exists: most of the psychiatric cases that are seen in clinical practice receive some form of psychotropic drug treatment [17].

Many seasoned clinicians, in all specialties and types of practice, may perceive that there is something wrong with the approach dictated by the EBM model. However, they are reluctant to shout that the emperor has no clothes, because the scientific literature is compact, with very few exceptions, in praising the emperor's clothes. Younger physicians who have been trained to adhere to guidelines are convinced to apply the best evidence and are not aware that they are simply guided to see problems in a certain way by vested interests and to treat the average instead of the individual patient. The net result is a degradation of clinical practice and, indeed, there is no evidence that EBM has improved clinical practice [15].

The problem is that we live in an age of transition: there are signs, if we do not refuse to see them, of the decline and fall of the Cochrane empire $[4,18]$, but it is difficult to foresee alternative conceptual frameworks. This journal is working on building such pathways [4]. Like a laboratory we are trying to remove the conceptual obstacles to the progress of clinical practice and research, to foster pluralism, and to host innovations in assessment and treatment.

The journal has increased again its impact factor (IF) in 2019 (14.86) and continues its growth. The new IF places Psychotherapy and Psychosomatics as third in the Science Citation Index Psychology ranking and fourth in the Science Citation Index Psychiatry ranking. These rankings, however, do not differentiate whether a journal is exclusively concerned with review articles (that are more likely to be cited) or publishes also original investigations. In the Science Citation Index Psychology ranking, the 2 journals preceding Psychotherapy and Psychosomatics are exclusively dedicated to review articles. This indicates that Psychotherapy and Psychosomatics is the top journal for original investigations in psychology.

Such achievement is the result of several converging efforts. We first like to acknowledge here the work of the editorial board and statistical consultants; the help of many external reviewers (listed below), who dedicated their time and efforts to assess and improve the quality of 
submitted manuscripts; the skills of Emanuela Offidani and Andrea Sabbatini who prepared the press releases of the published articles; and the support of our authors and readers.

The following experts have supplemented the editorial board by reviewing the manuscripts submitted to Psychotherapy and Psychosomatics during 2020 and are gratefully acknowledged.
A. Abbass (Halifax, NS, Canada)
U. Albert (Trieste, Italy)
C. Baethge (Cologne, Germany)
L. Bang (Oslo, Norway)
B. Becker (Chengdu, China)
G. Benasi (Bologna, Italy)
M. Benros (Copenhagen, Denmark)
A. Biffi (Milan, Italy)
J. Bisby (London, UK)
J. Boswell (Albany, NY, USA)
C. Bousman (Calgary, AB, Canada)
R. Cáceda (Stony Brook, NY, USA)
D. Carrozzino (Bologna, Italy)
G. Casu (Bologna, Italy)
R. Caudill (Louisville, KY, USA)
M. Cheung (Singapore)
D. Cohen (Los Angeles, CA, USA)
L. Colloca (Baltimore, MD, USA)
C. Cusin (Boston, MA, USA)
N.C. de Clercq (Amsterdam, The Netherlands)
P. Cuijpers (Amsterdam, The Netherlands)
J. de Figueiredo (Cheshire, CT, USA)
K. Demyttenaere (Leuven, Belgium)
M. Dold (Vienna, Austria)
S. Dubovsky (Buffalo, NY, USA)
S.E. Eisendrath (San Francisco, CA, USA)
C. Fernandez Robles (Yale, CT, USA)
R. Fielding (Hong Kong, China)
P. Fink (Aarhus, Denmark)
D. Finniss (Sydney, Australia)
M.P. Fleck (Porto Alegre, Brazil)
D. Fujisawa (Keio, Japan)
M.A. Fullana (Barcelona, Spain)
T. Furukawa (Kyoto, Japan)
E.-L. Garland (Salt Lake City, UT, USA)
S.B. Goldberg (Madison, WI, USA)
H. Gündel (Ulm, Germany)
M.P. Hengartner (Zurich, Switzerland)
S. Hennebicq (Grenoble, France)
M. Horowitz (London, UK)
J. Hoyer (Dresden, Germany)
R. Hurlemann (Bad Zwischenahn, Germany)

S. Jernelov (Stockholm, Sweden)

D. Kavanagh (South Brisbane, QLD, Australia)

C.H. Kellner (Charleston, SC, USA)

J.P. Klein (Lübeck, Germany)

R. Klinger (Hamburg, Germany)

O. Kohler-Forsberg (Aarhus, Denmark)

J. Lancee (Amsterdam, The Netherlands)

H.-Y. Lane (Taichung, Taiwan)

J.H. Lee (Seoul, Korea)

F. Leichsensring (Giessen, Germany)

K. Lim (Minneapolis, MN, USA)

A. Lindahl-Norberg (Stockholm, Sweden)

M. Linden (Berlin, Germany)

D. Linder (Venice, Italy)

C. Lloyd (Milton Keynes, UK)

M. Loflin (San Diego, CA, USA)

D. Loparo (Atlanta, GA, USA)

L. Lorenzo-Luaces (Bloomington, IN, USA)

J. Luccarelli (Boston, MA, USA)

M. Lucente (Bologna, Italy)

E.-L. Maggioni (Milan, Italy)

J. Margraf (Bochum, Germany)

R. Mojtabai (Baltimore, MD, USA)

A.M. Monteleone (Naples, Italy)

F.A. Mustafa (Northampton, UK)

I. Niedhammer (Angers, France)

I. Noack (Berlin, Germany)

J. Ogrodniczuk (Vancouver, BC, Canada)

G. Papakostas (Boston, MA, USA)

C. Patierno (Bologna, Italy)

R. Procyshyn (Vancouver, BC, Canada)

L. Rapport (Windsor, ON, Canada)

K. Rickels (Philadelphia, PA, USA)

W. Rief (Marburg, Germany)

J. Roache (San Antonio, TX, USA)

G. Rodin (Toronto, ON, Canada)

C. Salzman (Boston, MA, USA)

K. Schag (Tübingen, Germany)

C. Schulz Quach (Toronto, ON, Canada)

R. Schuster (Salzburg, Austria)

E. Silberman (Boston, MA, USA)

O.R.F. Smith (Oslo, Norway)

V. Spoormaker (Munich, Germany)

K. Stocker (Zurich, Switzerland)

K.-P. Su (Taichung, Taiwan)

R. Susukida (Baltimore, MD, USA)

J.J. ter Heide (Diemen, The Netherlands)

M. Thase (Philadelphia, PA, USA)

B.D. Thombs (Montreal, QC, Canada)

A. Tsutsumi (Sagamihara, Japan) 
S. Unterecker (Würzburg, Germany)

A. van Schack (Amsterdam, The Netherlands)

C.M. van der Feltz-Cornelis (Heslington, UK)

A. van Emmerik (Amsterdam, The Netherlands)

J. Wei (Beijing, China)

R. Weiner (Durham, NC, USA)

J. Wildes (Chicago, IL, USA)

K. Winkley (London, UK)

S.Y.S. Wong (Hong Kong, China)
Y. Wu (Montreal, QC, Canada)

Y. Zhai (University Park, PA, USA)

B. Zhu (Bologna, Italy)

\section{Conflict of Interest Statement}

Both external referees and editorial board members have disclosed potential conflicts of interests. The Editor-in-chief and the Associate Editors have no conflicts of interest to declare for 2020.

\section{References}

1 Fava GA. The clinical factor. Psychother Psychosom. 2011;80(1):1-3.

2 Balon R. The clinical factor 2016. Psychother Psychosom. 2017;86(6):323-31.

3 Ioannidis JP. Evidence-based medicine has been hijacked: a report to David Sackett. J Clin Epidemiol. 2016;73:82-6.

4 Fava GA. The decline of pluralism in medicine: dissent is welcome. Psychother Psychosom. 2020;89(1):1-5.

5 Krimsky S, Rothenberg LS, Stott P, Kyle G. Scientific journals their authors' financial interests: a pilot study. Psychother Psychosom. 1998;67(4-5):194-201.

6 Ryff CD, Singer B. Psychological well-being: meaning, measurement, and implications for psychotherapy research. Psychother Psychosom. 1996;65(1):14-23.

7 Fava GA. The concept of recovery in affective disorders. Psychother Psychosom. 1996; 65(1):2-13.
8 Fava GA. Do antidepressant and antianxiety drugs increase chronicity in affective disorders? Psychother Psychosom. 1994;61(3-4): 125-31.

9 Cosci F, Chouinard G. Acute and persistent withdrawal syndromes following discontinuation of psychotropic medications. Psychother Psychosom. 2020;89(5):283-306.

10 Fava GA, Guidi J, Rafanelli C, Sonino N. The clinical inadequacy of evidence-based medicine and the need for a conceptual framework based on clinical judgment. Psychother Psychosom. 2015;84(1):1-3.

11 Feinstein AR, Horwitz RI. Problems in the "evidence" of "evidence-based medicine". Am J Med. 1997;103(6):529-35.

12 Fava GA, Guidi J, Rafanelli C, Rickels K. The clinical inadequacy of the placebo model and the development of an alternative conceptual framework. Psychother Psychosom. 2017; 86(6):332-40.
13 Horwitz RI, Singer BH, Makuch RW, Viscoli CM. Can treatment that is helpful on average be harmful to some patients? A study of the conflicting information needs of clinical inquiry and drug regulation. J Clin Epidemiol. 1996;49(4):395-400.

14 Reuben DB, Tinetti ME. Goal-oriented patient care- An alternative health outcomes paradigm. N Engl J Med. 2012;366(9):777-9.

15 Fava GA. Evidence-based medicine was bound to fail: a report to Alvan Feinstein. J Clin Epidemiol. 2017;84:3-7.

16 Medication Overload: America's Other Drug Problem. Brookline, MA: Lown Institute; April 2019.

17 Fava GA, Rafanelli C. Iatrogenic factors in psychopathology. Psychother Psychosom. 2019;88(3):129-40.

18 Concato J, Horwitz RI. Limited usefulness of meta-analysis for informing patient care. Psychother Psychosom. 2019;88(5):257-62. 